\title{
FOREWORD
}

\section{Traumatic Brain Injury and Its Management}

This latest issue of Seminars in Speech and Language is in response to a questionnaire sent to readers last year. At that time, readers indicated strongly that they wished to be updated on the treatment of traumatic brain injury (TBI). It is fortuitous that the Academy of Neurologic Communication Disorders and Sciences (ANCDS) was completing its practice guidelines on TBI at that time. Seminars was well positioned to publish one of its major compilations concerning clinical management.
This issue represents truly state-of-the-art treatment and assessment research concerning TBI. I thank Lyn S. Turkstra, Ph.D., and the authors she has assembled to complete this issue. All of you recognize the authors as outstanding contributors to our knowledge concerning TBI and its management.

Audrey L. Holland, Ph.D.
Co-Editor in Chief 